\title{
Business Models in the Mobile Ecosystem
}

\author{
Ruixue Xia \\ Mobile Life Centre \\ Stockholm University \\ Stockholm, Sweden \\ sallyxia_2002@hotmail.com
}

\author{
Mattias Rost, Lars Erik Holmquist \\ Mobile Life Centre \\ SICS \\ Stockholm, Sweden \\ \{rost, leh\}@sics.se
}

\begin{abstract}
The mobile ecosystem is constantly changing. The roles of each actor are uncertain and the question how each actor cooperates with each other is of interest of researchers both in academia and industry. In this paper we examine the mobile ecosystem from a business perspective. We used five mobile companies as case studies, which were investigated through interviews and questionnaire surveys. The companies covered different roles in the ecosystem, including network operator, device manufacturer, and application developer. With our empirical data as a starting point, we analyze the revenue streams of different actors in the ecosystem. The results will contribute to an understanding of the business models and dependencies that characterize actors in the current mobile ecosystem.
\end{abstract}

Keywords-business models; mobile ecosystem

\section{INTRODUCTION}

Mobile business is a rapidly growing industry providing mobile devices, contents and services. Like many other new emerging businesses, mobile business possesses the characteristics of innovative technologies, critical mass of users, incredibly fast changing environment. Although the business environment have been around for a few decades, the emergence of smart phones and advanced mobile services and applications have started to change it.

The emergence of app stores and various application developers have already stimulated each part of the mobile chain, such as operators, developers, manufacturers, and OS platform owners. As many agree that Apple's business model is one of the most successful ones in the ubiquitous environment, most actors of the industry are trying to follow Apple's success, launching app stores of their own. However, it reaches broad consensus that "there is no universal business model that can apply to all the cases arising from the various factors, for instance economical, social, demographical and political factors, in different regions" [1]. The problem we are facing today is that the old business models are not suitable for the new era of mobile business.

Previous research has given various definitions of business models from different perspectives. As explained by Camponovo and Pigneur [2], "a business model provides a description of the roles and relationships of a company, its customer, partners and suppliers, as well as the flows of goods, information and money between these parties and the main benefits for those involved, in particular, but not exclusively the customer." Every industry has its own characteristic business model to sustain itself. Osterwalder and Pigneur proposed an e-Business model ontology, in which he proposed business model as a conceptual tool that contains a set of elements, covering all aspects of the value chain, including the infrastructure, offerings, customers, and finance [3]. Specifically speaking, the ontology describes the value the firm offers to its customer, the architecture of its partners' relationships, the approach to deliver its products, and the generated profits through a variety of revenue streams.

At the same time, with the coming of more advanced mobile services, the mobile access is becoming more ubiquitous and open. The mobile advertising model, the pricing model, the subscription model, the retail model and the SMS model are all changing dramatically each day. These models will be addressed briefly later.

The key questions to this research can be summarized as follows:

- What are the current business models of each important participants of mobile industry from academic research perspectives?

- How do these participants affect and influence each other in the mobile value network?

The research will be adopted in both theoretical and empirical approach. In order to obtain the specific data and information, and complicated details in the mobile industry, besides theory study from reviewing literatures, we will conduct interviews and questionnaire surveys within selected telecom and mobile companies representing various parts of the ecosystem, such as manufacturers, mobile network operators, and developers. The companies and organizations that we interview become the cases to be studied during the research.

The structure of this paper is as follows. First we will present related work in the area. We will then present the current stakeholders and give examples of successful business models. This will be followed up by a description of a set of case studies of various stakeholders in the mobile ecosystem with unique roles. This is then followed by an analysis and a presentation of a framework into which the stakeholders are put. 


\section{RELATED WORK}

Previous studies of mobile business principally adopted the value chain methodology or some extended ones, for instance the value web and service networks methodology. Catanzaro, Rangone, Renga \& Valsecchi exploited the presence of new value chains for media companies to distribute their contents on mobile phones and gave an empirical analysis of revenue subdivision along the value chain [4]. A taxonomy for the mobile industry within the value web has been investigated in studies of mobile business [5]. Carleen, Elisabeth, Uta, Harry examined interorganizational service networks of mobile companies through which mobile information and entertainment services are delivered [6]. There has also been research on business models regarding value chains for online content on mobile platforms. Reference [7] lay out a framework for analyzing the roles played by stakeholders in the consumption, distribution, and production of mobile content. Ballon et al [8] investigated the value network of an advertisement-based platform for mobile operators and describe how different actors strive to exercise control within the business model.

The early investigations of network-centric mobile business have attributed to restructuring the value network in the mobile market from vertically to horizontally, but it is hard to comprehensively analyze the mobile business from different complementary perspectives. However, the business model framework proposed by Osterwalder and Pigneur can be applied to analyze the roles and relationships of all the players within the industry. Our work is based on this framework tool and extends a research program for mobile services in Mobile Life [9] to investigate the existing business models and how stakeholders coexist in the current mobile ecosystem.

\section{THE MobILE ECOSYSTEM}

Here we will present the actors and current models in the mobile ecosystem. We will begin with the different stakeholders, and end with some examples of mobile business models.

\section{A. An overview of the stakeholders}

The mobile market is very fragmented, and requires its actors to collaborate with each other to successfully offer complete services to the consumers. We will therefore begin by giving an overview of the stakeholders.

1) Mobile network operator

A mobile network operator (MNO), as Bormann, Flake, Tacken [10] said is a telephone company that "operates the access network infrastructure, delivers basic services to the user (e.g., Voice, SMS, Internet Access)", provides mobile devices, and controls the billing systems for the customers' usage.

For the mobile network function, the MNO "plans the network architecture and topology, acquires (buys or leases) and develops (in terms of civil engineering) the sites needed for rolling out the network, oversees the network implementation by suppliers and subcontractors, and operates and maintains the network" [11]. The network is migrating increasingly rapid in recent years. Up to now, the 3rd generation $(3 \mathrm{G})$ wireless network has been adopted in most MNOs, followed by the recent upgrading to $4 \mathrm{G}$ networks after the amount of data traffic from surfing social networks is rapidly increasing.

Apart from basic mobile services like voice call, SMS, and internet access, under $3 \mathrm{G}$ environment, MNOs offer digital contents, for instance ringtones, images, applications, etc through their portals [10].

\section{a) Mobile virtual network operator}

Besides MNOs there are also mobile virtual network operators (MVNOs) active in the mobile market. They offer mobile communications services to end users without having their own radio spectrum, and do not own licenses but must lease network capacity or equipment from licensed operators.

It is quite hard to judge if the positive influences brought by the emergence of MVNOs outweigh the negative ones for the MNOs as a whole. Some MVNOs are run by content owners and developers, who attempt to create a distribution channel to promote their applications and services directly to the customers by their own. The market sharing inevitably offers competition to the MNOs, but on the other hand MNOs would like to outsource their excess capacity and products to MVNOs to be able to focus on their specific targeted segments of business.

\section{2) Handset manufacturers}

Mobile handset manufacturers are the providers of mobile devices. Besides mobile handsets with a variety of rich features, the manufacturers also produce products like mobile phone accessories and other telecom equipments.

Currently, the mobile handset market is hyper competitive, price-driven, and "feature-conscious", which creates a significant challenge for mobile handset manufacturers - to remain competitive, maintain and increase margins and ensure the phone is the one that consumers are demanding [12].

3) Mobile operating system

A mobile operating system, similar to a desktop operating system for computers, is an interface between the mobile device and the user, which controls and manages the resources to make sure the mobile applications are working on the device.

Major operating systems in the mobile market include Symbian OS, Blackberry OS, Palm OS, Windows Mobile, iPhone OS, Binary Runtime Environment for Wireless (BREW), Linux, and Android.

\section{B. Some examples of mobile business models}

In order to have a thorough understanding of the mobile market, we also need to have a look at some examples of business models from the mobile service perspective in which the stakeholders play their roles.

\section{1) Revenue model}

Coursaris, Hassanein, and Head studied the mobile revenue model from a company or an organization's perspective [13]. They divide the mobile revenue model into 
eight sub-models, including access model, subscription model, pay-per-use, "advertising, transaction, payment clearing, hosting, and point-of-traffic" [13], in which subscription model and advertising model have already been studied in detail in our paper just now.

Camponovo and Pigneur studied the mobile revenue models from the mobile actors' perspective. Similar to Osterwalder and Pigneur defining "revenue model as the capability of translating customer value proposition into cash flow, namely the incoming revenue stream" [3], they examined the revenue streams of different actor groups, i.e. mobile device manufacturers, network equipment vendors, content and application providers, payment agents, mobile operators, regulators, etc.

\section{2) Mobile advertising model}

In connection with the development of mobile technologies, mobile advertising is a relatively young but rapidly growing sector in the mobile ecosystem to offer companies good opportunities on the mobile devices to connect with their possible consumers. Hanna, et al. [14] claim mobile advertising model as it "offers potential revenue-generating opportunities for a number of different actors".

The Mobile Marketing Association (MMA) concluded four channels delivering the mobile advertising to reach the consumers in Mobile Advertising Overview [15], i.e. mobile websites, mobile applications, mobile messaging and mobile video.

3) i-mode in Japan

i-mode, created by NTT DoCoMo, is a popular mobile service in Japan, whose emergence significantly changed the Japanese mobile industry for ten years. NTT DoCoMo created the i-mode service by "first defining the entire architecture and functionality in the device and then delivering the specification to a number of device manufacturers" [5], various departments at DoCoMo, content providers, and other platforms to ensure a jointly evolution of technologies and user experiences.

Compared to Wireless Application Protocol (WAP), imode gives the users access to information or services through a wider variety of internet protocols and data format, for instance C-HTML, and the packet-switched network, etc [16]. Moreover, DoCoMo has developed C-HTML, which is a fixed Internet data formats based on HTML, and a graphic interface format.

A lot of research has been conducted to study what business model leads to the success of i-mode [17] [18] [19]. NTT DoCoMo themselves concluded three important factors, which are i-mode collaboration concept, content quality control, and simple price system.

i-mode success shows the case that "the MNO on the market single-handedly decided how an entire concept should work" [5], thereby eliminating the standard services problem. So it has a very close relationship with the device manufacturers, content providers, ISPs, and platform vendors, and searches for a win-win situation in every relationship.

\section{CASE STUDY}

The research aim is to give a comprehensive overview of the mobile ecosystem's business models, so it is necessary to investigate each participant of mobile industry, and analyze how they cooperate and compete with each other to get a win-win situation. We interviewed five companies for the latter case studies of our research, i.e. TeliaSonera, Sony Ericsson, Squace, Bluewalks, and Bloo, representing the perspectives of mobile network operators, handset manufacturers, content providers, and application developers respectively.

MNOs act as bridges among all other actors through their network and subscriptions. No one can live without operators in the mobile industry. But in the current diverse market, the operators are also facing big challenges, for instance the manufacturers' app stores, MVNOs, etc, competing with the market share. In this case, I chose TeliaSonera, one of the biggest operators in Nordic countries to study its connections with other actors, and the solutions to solve those problems and challenges.

Sony Ericsson is considered the most popular brand of mobile phones in Sweden. It has good relationships with carriers, content providers, and application developers to help it provide mobile phones with rich features. Its business models with content providers are therefore valuable to study.

Squace is a Swedish mobile software company that provides universal mobile interface software for various mobile devices. The interface is a mobile browser collecting contents and mobile services, popular sites like Facebook, Twitter, and YouTube into one desktop. Squace claims free of charge for users, so how it makes profit out of it is an interesting question.

Bluewalks and Bloo are both new startups. Bluewalks develops a platform on which people can share their routes of real life, while Bloo "enables people to communicate when they are geographically close to each other" [20]. It is quite difficult to see any evident business model around these two companies at the moment, but they are representing millions of new startups targeting mobile applications who want to share a piece of cake in the new era of the mobile market. It is quite interesting to study what possible business models they are going to adopt when facing such large amounts of distribution channels for their applications.

\section{A. TeliaSonera}

\section{1) With device manufacturers}

TeliaSonera is cooperating with handset manufacturers regarding the bundling with the devices and subscriptions. They pick the terminal devices that are preconfigured with settings and its hot spots that make sure the customers can use the mobile services with its network in a good way, and get the access to its portal easily. They do not have much revenue sharing, because it is just a buying and selling relationship.

2) With 3rd party content providers and application developers 
TeliaSonera has its own branded content, for instance TeliaSonera Music Player. There are also other game services as well. Telia Entertainment Service team is mainly responsible for their operating. TeliaSonera implements the functionality, features and some development of the services. But normally it is the 3rd party content providers that provide and manage the services background. The contents and applications are developed by those 3rd party content providers or application developers, sold to TeliaSonera, and branded as TeliaSonera applications.

Some contents and services provided by 3rd party content providers are keeping their own brand names, though they are using the TeliaSonera portal. They are usually very popular and most used brands, such as Disney, and Microsoft services, for instance MSN messenger. They are just using TeliaSonera's market channels to distribute themselves to the end users. Therefore TeliaSonera 3rd party portal contain both its own branded services and some external 3rd party branded services.

\section{3) With MVNOs}

MVNOs are competing with TeliaSonera in the prices and services offered to the end users. But MVNOs are virtual operators, which means that they do not own the network. TeliaSonera however sell the capacities to them. So it is hard for the MVNOs to become a big threat and dispute much market share with TeliaSonera.

\section{B. Sony Ericsson}

\section{1) With mobile network operators}

In Sweden, when Sony Ericsson sells the devices, they are just playing the hardware of the mobile. The mobile network operators buy the phones from it, and it sells them in turn. So there's no revenue sharing between them.

\section{2) With content providers}

When it comes to the contents, Sony Ericsson plays part of as a developer, as well as a music company or movie company, for instance Sony Ericsson PlayNow ${ }^{\mathrm{TM}}$. Sony Ericsson talks to the content providers about possible ways for them to produce contents for it which it will include in the mobile phones, either preloaded, or through some sorts of access means like PlayNow ${ }^{\mathrm{TM}}$. The revenue depends on the negotiation with the content providers. The content provider gets the money each time the content is got accessed.

\section{3) With application developers}

When it comes to the application developers, Sony Ericsson has a developer program where it tries to make tools available, such as the API, and the whole environment to let the application developers come in and write their own applications. Regarding the revenue, Sony Ericsson has third revenue split with them in the app store. Basically the developers get $70 \%$, while Sony Ericsson gets $30 \%$ of the applications transactions.

\section{Squace}

Squace is a free mobile application that lets the users collect the most often used mobile websites, services and information into one homepage. This application is above the mobile network operators, which means that it has no collaboration with the operators. Users who use this application only have to download the application for free, and pay for the data traffic from the operators every time they get access to the internet.

Squace is also free of charge for content providers and application developers, but it does some consulting when they need help with integration into the application, which is one, but not the key revenue source.

Another revenue resource of Squace comes from an advertising model. "Squace interface is built up by squares where each square represent a site or content of any kind" [21]. There are certain sites and links that are by defaults in the squares, for instance CNN news, Aftonbladet, etc. There are also some sponsored links in the bottom bar. They pay for the appearance in its first pages or in the bottom bar.

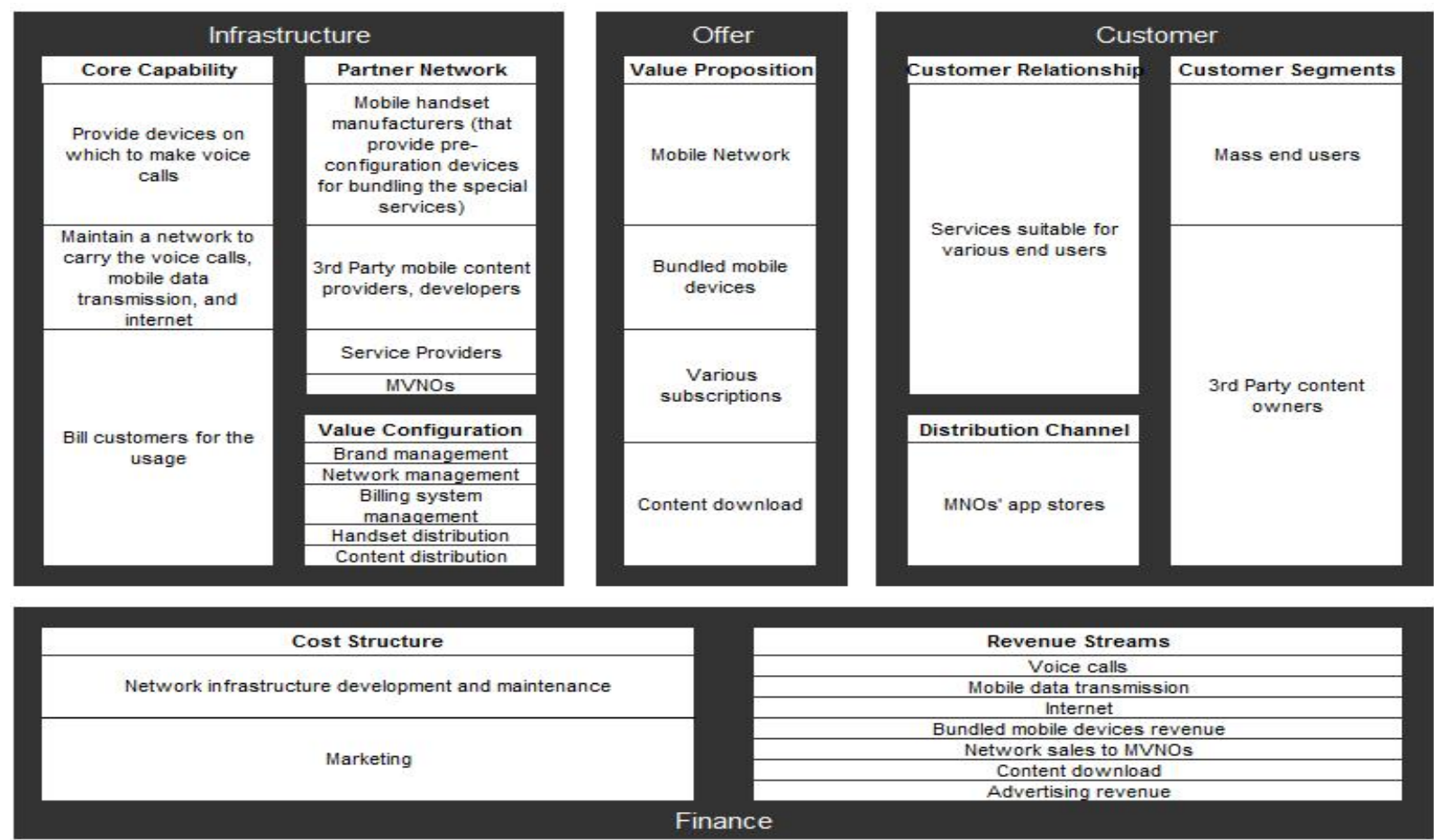

Figure 1. Business Model of Mobile Network Operator 
Once the users register through Squace and start to use the service, Squace gets money out of it then.

\section{Bloo}

Bloo AB is a start-up Swedish mobile company, developing online chat application, called BlooFlirt. BlooFlirt is built on a platform that Bloo developed itself, which is a new way of positioning by using Bluetooth. The solution is operator independent and works on almost every mobile phone model in all mobile network connection today (GPRS/WiFi/3G/EDGE etc). All the users need to do is to connect to the internet. Therefore it does not cooperate much with mobile network operators, only if the application is sold in operators' app stores.

Open APIs of the platform are planning to be released so that any developers can write their own applications on it. To have the application running on all devices, they are using a new SDK that provides to do cross platform compilation to all platforms (Symbian, Android, Java, Windows Mobile etc). This is the way that how they work with other mobile application developers and content providers.

Regarding the payment, BlooFlirt is free to use for everyone, but some extra functionalities will be charged. Users pay for the extra services through a premium SMS automatically after they accept the payment for the application, which simplified the process of subscribing. Apart from the revenue of extra functionalities, another stream that BlooFlirt is thinking about is mobile advertisements.

\section{E. Bluewalks}

Bluewalks is a free platform for people to express and share their real life experience through creating and sharing routes. The service can be access from its website, or downloaded from iPhone app store. When a subscriber intends to download this application through the app store, he/she will be charged a fee, which becomes revenue to be shared between Bluewalks and iPhone, $70 \%$ and $30 \%$ respectively. Operators have nothing to do with it, but charge the data traffic fee for the usage of the service.

\section{ANALYSIS OF BUSINESS MODELS OF MOBILE ECOSYSTEM}

In this chapter, we will present the findings drawn from the results of the case studies in the previous part, and give a comprehensive analysis for our business models design for the major participants of the mobile ecosystem.

\section{A. MNO business model design}

The case study with TeliaSonera demonstrates that mobile network operators have always been playing one of the most critical roles in the mobile ecosystem, no matter which kind of business model is dominant in the ecosystem. Figure 1 above is our design of operators' business model based on the framework proposed by Osterwalder [3].

\section{1) Offer, infrastructure and customer}

\section{a) Mobile network}

Currently, however the operators are facing the increasing risk in being disintermediated from the mobile value chain, they are still controlling the network. So their major and basic value proposition is still to provide and maintain a network to carry the voice calls, mobile data transmission, and internet. Currently, there are more and more advanced applications and services developed in the market, which requires the operators to enhance and upgrade their core capabilities in networking. $3 \mathrm{G}$ network is the one they are mostly promoting at the moment. Operators, such as TeliaSonera even start to launch $4 \mathrm{G}$ so as to satisfy the needs of their customers and make sure they can enjoy the best experience on mobile.

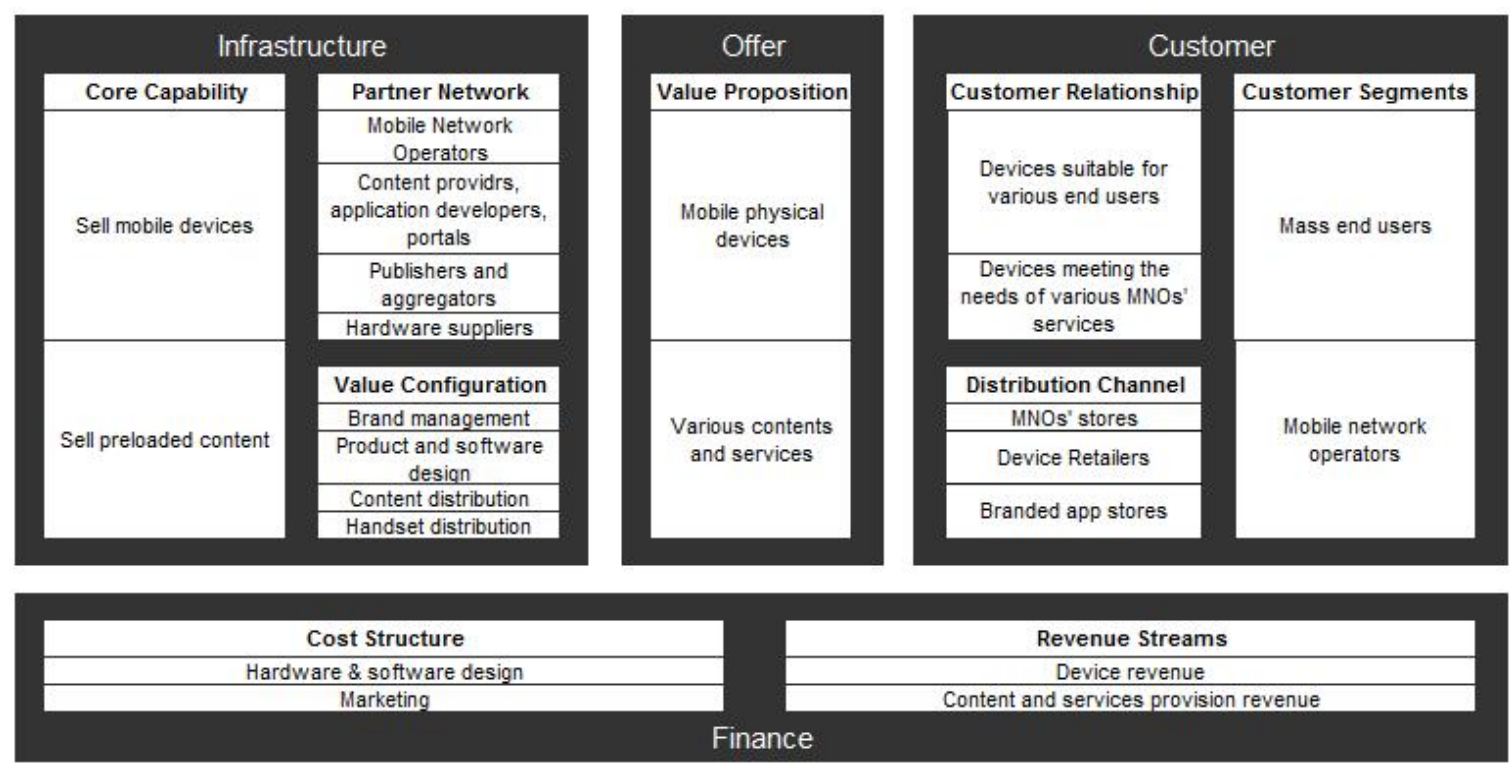

Figure 2. Business Model of Handset Manufacturer 


\section{b) Bundled mobile handsets}

In Europe, US, and especially Japan, most consumers get their mobile devices through local mobile network operators' stores. From our interview, it is not difficult to see that TeliaSonera, together with all other operators in Sweden, follows the tradition that sells bundled mobile devices in their retail stores. It is basically a collaboration between the operators and manufacturers - the manufacturers make the unique featured phones meeting the specific requirements of operators, such as the capabilities in the network, with which customers can use their mobile data and SMS, and some preconfiguration and settings of the phone, e.g., some preloaded hot spot on the phone that customers can easily get access to operators' portal. This collaboration between the operators and manufacturers is a normal selling-and -buying, so there is no revenue split among them.

\section{c) Content}

In order to succeed in the crowded mobile market, operators almost all over the world start to share a piece of this big app store cake, which we can see from our case as well. The launching of TeliaSonera's app stores on one hand increases the opportunity of cooperation with manufacturers, $3^{\text {rd }}$ party content providers, and developers, and creates competitions on the other hand. These competitions are mainly from the increasing numbers of preloaded app stores in the bundled mobile devices, where the applications developers have more options to distribute and present their products. The one that can provide more compelling user experience can succeed in the competition in the end.

\section{d) Billing system}

Billing the customer for using the network helps the mobile network operators grasp the power in the ecosystem. "One way to accomplish this is Premium SMS billing", in which customer is billed at a premium rate of text message for the content from the content providers [22]. Other payments include direct to bill, credit cards, interactive voice response, stored value and prepaid or gift cards, some of which may not be involved with the operators' billing transaction, but the operators still get revenue from them, depending on the agreements between them and content developers or providers.

\section{2) Finance}

It is quite obvious that the major cost for the operators hasn't changed much, which still comes from network infrastructure development and maintenance. But their revenue source is no longer restricted to voice calls, broadband, and bundled devices. MNOs' branded mobile app stores are a new market which promises a new revenue stream for them [23]. In the interview with TeliaSonera, we get to know that they get the revenue from their branded app stores, and split with the developers, 3rd party content providers, handset vendors, and OS platform owners.

\section{B. Handset manufacturer business model design}

The handset manufacturers are the players that offer the physical handsets in the mobile industry. Devices, including mobile phones, PDAs, and even netbook, have been provided via various channels, such as operators' branded stores, manufacturers' own stores, and some device retailers. In Europe and Japan it is a common case that consumers buy the devices through operators, so manufacturers have the most bonding with them.

At present, mobile handsets are not only positioned as devices that can make voice calls and SMS, but have evolved to a platform with a rich variety of features that can conduct the function of business use, entertainment, social media, and information services. In addition, $3 \mathrm{G}$ enables a higher data network to transmit those rich features. So manufacturers start to launch branded app stores to offer various default configured contents and services, e.g. Sony Ericsson PlayNow $^{\mathrm{TM}}$.

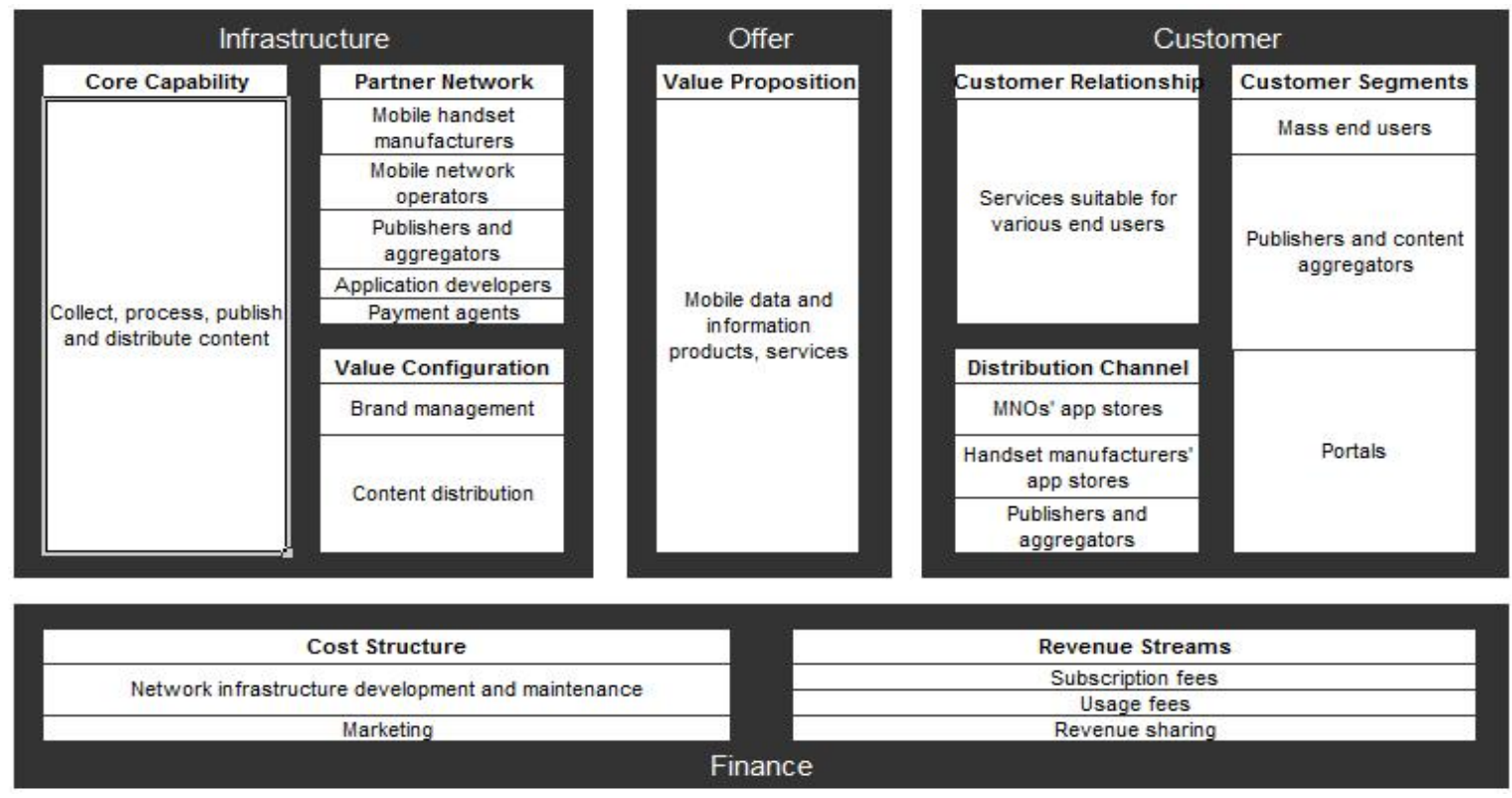

Figure 3. Business Model of Content Provider 
Among all the partners, the operators are very important one, because operators' retail stores are the most common distribution channel of their products. The manufacturers partner with application developers and content providers to develop mobile services and portals as well. For instance Sony Ericsson is working with GetJar, one of the biggest content aggregators.

Manufacturers' revenue mainly comes from the device sale and the revenue share of content and services provision with the content providers or application developers.

\section{Content provider business model design}

With the development of the whole mobile environment, mobile content is changing rapidly, evolving from the simple ringtones, graphics, and movies to applications and information services that affect all aspects of our lives. The content delivery thus has been changed as the content becomes diverse. When there were only ringtone and wallpaper contents before, only two methods of delivery existed, which are over the air, and sideloading.

Content providers are the mobile actors that prepare mobile data and information products, and services for the delivery and use, as well as facilitate the content exchange. They usually partner with a variety of distribution channels, which are MNOs' app stores or portals, manufacturers' app stores, and publishers and aggregators, in order to let the customers they target to access their products. Other partners that are useful for content providers to work with are the application developers, from which they can get all sorts of applications and software, and payment agents to get the micro-payment service. The revenue mainly comes from the end users' subscription fees, usage fees, and revenue split with the operators and manufacturers. Extra revenue comes from the mobile advertising fees.

\section{Application developer business model design}

Mobile application developer offers without any doubts various mobile applications and platforms for the end users. As the $3 \mathrm{G}$ networks nowadays achieve bigger network capacity, offering the developers great opportunities to produce a wider range of software and services. The types of applications they produce now cover all aspects of our lives, from music to fun and games, from work to working out, from cooking to traveling, etc. The cases we studied in this paper Bloo and Bluewalks offer online chatting software and location based service respectively.

Developers currently have more options to distribute and sell their applications, as almost all of the participants of the market have established app stores, not to mention the emergence of other content and service providers, and some publishers and aggregators.

The increasing distribution channels on the other hand gave birth to various new subscription and payment forms. Apart from the traditional credit cards payment and premium SMS subscription, there are some payment agents are founded to offer suitable payment methods to newly developed services. Application developers therefore have some connections directly with banks, or with these payment agents.

The revenue source for the developers mostly comes from the usage of the applications they produce. Constantinou claims that "mobile app stores are a new solution market which promises the development of a new revenue stream for operators, handset OEMs and application developers" [23]. Applications in the app stores are either free in charge for download, or include a small

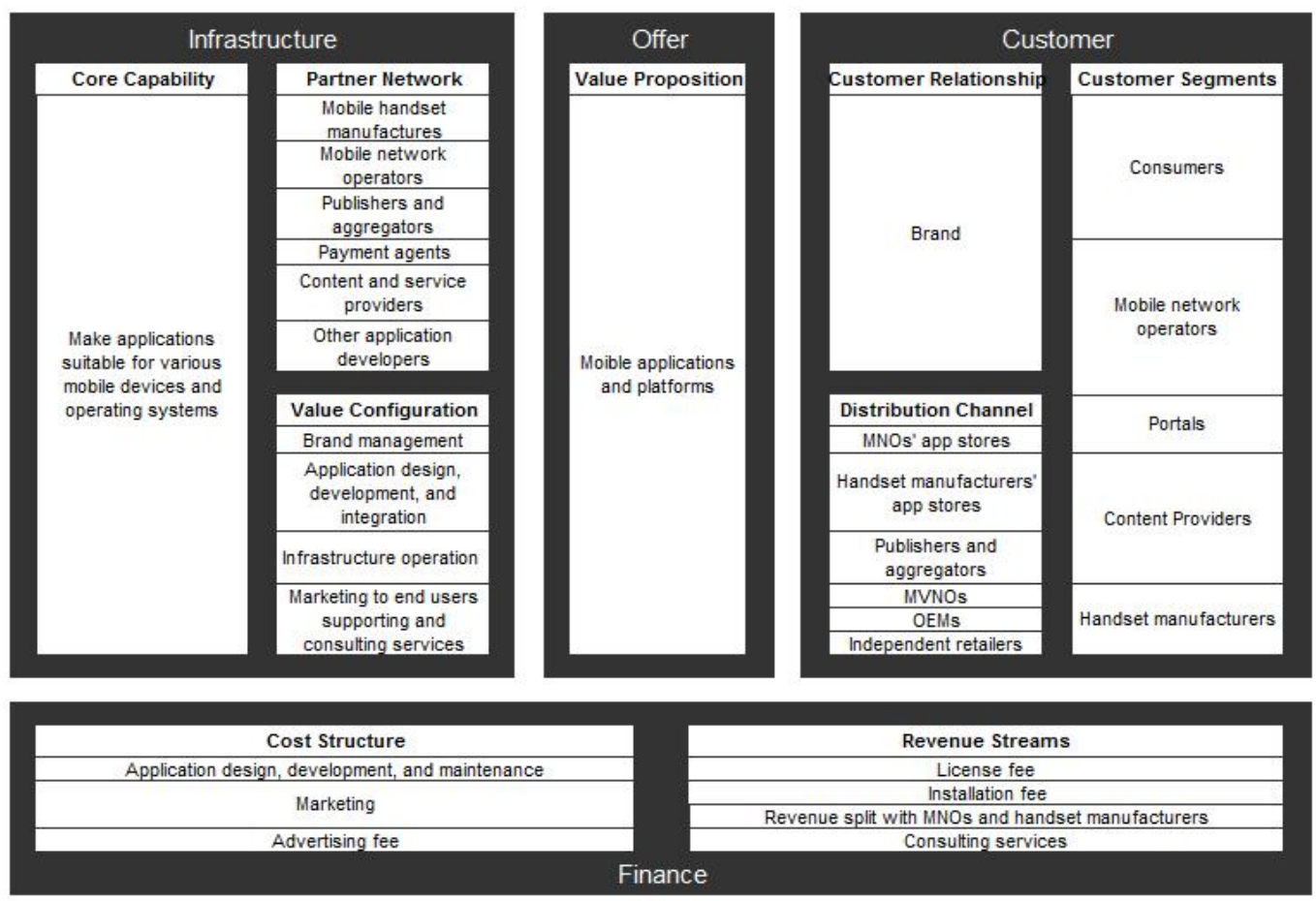

Figure 4. Business Model of Application Developer 
amount of license fee from the users. The license fee is one of the revenue for the application developers. Once the application is downloaded, users have to pay for the internet connection, or other stuff, which may concern with the revenue split for the operators and developers. Usually it follows the rules of 70-30 in the market, that is to say, the developers get the $70 \%$ of the revenue, while the operators get the other $30 \%$.

Some application developing companies, like Squace, have some consulting service for their applications or platforms, which will be included into their revenue sources.

\section{CONCLUSION}

In this paper we have given an overview of the mobile ecosystem and some common mobile business model examples, examined five selected mobile companies' positions in the market, designed the business models of major participants of the mobile ecosystem and presented a comprehensive analysis of them.

During our study of business models in the mobile ecosystem, we are surprised to find that mobile business is conducted not as plainly as we thought before. It is a huge complex network that is not merely a buying and selling relationship within the business. With the emergence of varieties of app stores, questions such as which app store is the best channel that the developers should deliver their applications through, how to deal with the problem of transferring services if the subscribers change the mobile network operators, and how much revenue that they should split with other alliances has to be dealt with.

Our research has shown the complexity of mobile business industry nowadays, in which all the participants are required to collaborate with each other. This is especially apparent when investigating our selected cases, as they try to involve all other actors if they want to win a favorable position in the market.

In this project, the studies of the whole mobile ecosystem business models arouse our interests of doing a larger study with the aim of business models from the perspectives of more participants involved in the mobile market to give a further and deeper understanding of mobile business in the near future.

\section{ACKNOWLEDGMENT}

We would like to thank those telecom companies for participating in our research and providing us invaluable information, and many thanks to our colleagues for their critique and advice.

\section{REFERENCES}

[1] H. Zhao, "Emerging business models of the mobile internet market," M.S. thesis, Helsinki University of Technology, Espoo, Finland, 2008.

[2] C. Giovanni, Y. Pigneur, "Business model analysis applied to mobile business," in 5th International Conference on Enterprise Information Systems, April 22-26, 2003, Angers, France. Lausanne: 2003.

[3] A. Osterwalder, Y. Pigneur, "An e-Business model ontology for modeling e-business," in 15th Bled Electronic Commerce Conference, June 17 - 19, 2002, Bled, Slovenia. Switzerland: 2002.
[4] C. Catanzaro, A. Rangone, F.M. Renga, and M. Valsecchi, "Media Company: An Empirical Analysis about the Mobile Channel," Proc. 2nd International Conference on Automated Production of Cross Media Content for Multi-Channel Distribution (AXMEDIS'06), IEEE Press, 2006, pp. 319 - 324, doi: 10.1109/AXMEDIS.2006.32.

[5] A. Kornak, J. Teutloff, and M. Welin-Berger, "Enterprise Guide to Gaining Business Value from Mobile Technologies," Hoboken, NJ: Wiley Publishing, Inc, 2004.

[6] F. M. Carleen, A.M. van de Kar Elisabeth, W. de M. Uta, and B. Harry, "Mobile information and entertainment services: business models and service networks," International Journal of Management and Decision Making., vol. 6 (1), pp. 47 - 64, 2005.

[7] R. Sharma, M. Morales-Arroyo, M. Tan, and S. Sangwan. "A business network model for delivering online content and services on mobile platforms," Proc. Global Mobility Roundtable, 2008.

[8] P. Ballon, N. Walravens, A. Spedalieri, and C. Venezia. "An Advertisement-based Platform Business Model for Mobile Operators," in $12^{\text {th }}$ International ICIN Conference, Bordeaux, France, 20-23 October, 2008 .

[9] L. E. Holmquist, K. Höök, O. Juhlin and A. Waern, "Mobile Life: A Research Foundation for Mobile Services," Proc. Global Mobility Roundtable, June 1-2, 2007, Los Angeles, California.

[10] F.C. Bormann, S. Flake, J. Tacken, "Business models for local mobile services enabled by convergent online charging," in $16^{\text {th }}$ Mobile and Wireless Communications Summit, 1 - 5 July 2007, Budapest, Hungary, 2007.

[11] T. Frisanco, P. Tafertshofer, P. Lurin, and R. Ang, "Infrastructure Sharing and Shared Operations for Mobile Network Operators: From a Deployment and Operations View," in Network Operations and Management Symposium (NOMS, 2008), 7-11 April 2008, Salvador, Brazil. 2008.

[12] Sarantel Ltd., "Consumer use of Location Based Services on Mobile handsets," 2009, [Online]. Available: http:/www.sarantel.com/ [Accessed: Jan. 18 ${ }^{\text {th }}, 2010$ ].

[13] C. Coursaris, K. Hassanein, M. Head, "Understanding m-Commerce: A Consumer Centric Model," Quarterly Journal of Electronic Commerce., vol 3, No. 3, 2002.

[14] K. Hanna, M. Tuija, S. Jaakko, T. Jaana, and U. Pauliina, "Business models in the emerging context of mobile advertising," E-business Review, 1, 2004.

[15] Mobile Marketing Association, "Mobile advertising overview," 2008, [Online]. Available: www.mmaglobal.com [Accessed: Jan. 20 ${ }^{\text {th }}, 2010$ ]

[16] "I-mode," 2009, [Online]. Available: http://en.wikipedia.org/wiki/Imode [Accessed: Dec. 2nd, 2009].

[17] L. Ye, H. Lin, "Which one should be chosen for the mobile geographic information service now, WAP vs. i-mode vs. J2ME?" Mobile Networks and Applications, vol. 11, pp. 901-915, 2006.

[18] T. Kiyoyuki, "DoCoMo's challenge towards new mobile services," Special interest tracks and posters of the 14th international conference on World Wide Web, May 10-14, 2005, Chiba, Japan.

[19] V. Peltokorpi, I. Nonaka, M. Kodama, "NTT DoCoMo's Launch of Imode in the Japanese Mobile Phone Market: A Knowledge Creation Perspective," Journal of Management Studies., vol. 44, pp. 50-72, 2007.

[20] Bloo AB, "Home page", 2009, [Online]. Available: www.bloo.se [Accessed: Jan. 5th, 2010].

[21] Squace, "Home page," 2010, [Online]. Available: http://www.squace.com/about/ [Accessed: Feb. 20 $\left.0^{\text {th }}, 2010\right]$.

[22] Strategy Analytics, Inc, "Understanding the mobile ecosystem: A White Paper Prepared for Adobe Systems Incorporated," 2008, [Online]. Available: http://www.adobe.com/devnet/devices/articles/mobile_ecosystem.pdf [Accessed: Feb. 16th, 2010].

[23] A. Constantinou, "The Mobile Application Store phenomenon," 2008, [Online]. Available: http://www.visionmobile.com/blog/2008/11/themobile-application-store-phenomenon/ [Accessed: Feb. 18 ${ }^{\text {th }}, 2010$ ]. 